\title{
Assessing Senior Secondary School Physics Teachers' Pedagogical Content Knowledge (PCK) Components Using Parks' Pentagon Model
}

\author{
Abubakar Sa'adatu Mohammed (Ph.D)* and Johnson Enemi Andrew \\ Department of Science Education, Abubakar Tafawa Balewa University, Bauchi, Nigeria \\ *Corresponding author
}

\begin{abstract}
Teaching is not the simple transmission of information but a complex act that require teachers to apply knowledge from multiple domains in order to facilitate students' learning. This paper reports the first part of a study that explored secondary school physics teachers' pedagogical content knowledge (PCK) components: (a) Orientations toward Teaching Science, (b) Knowledge of Student Understanding, (c) Knowledge of Instructional Strategies and Representations, (d) Knowledge of Science Curriculum, and (e) Knowledge of Assessment of Science Learning. The research adopted qualitative case study research design within Bauchi metropolis. The population of the study consists of twenty five (25) SS II physics teachers out of which two were sampled purposely. Data sources included classroom observations, semi - structured interviews guide, teacher's lesson plans, audio recorder and video-taper. Data were analyzed through three different approaches: (a) in-depth analysis of explicit PCK, (b) enumerative approach, and (c) constant comparative method. Data analysis indicated five salient features of the integration of the PCK components: (a) the integration of the components was idiosyncratic and topic-specific; (b) Knowledge of Physics Curriculum and Knowledge of Instructional Strategies and Representations has most limited integration; (c) Knowledge of Students Understanding and Knowledge of Assessment of Physics Learning had high interaction with other components; (d) Knowledge of Assessment of Physics Learning was poorly connected with Knowledge of Student Understanding and Knowledge of Instructional Strategies and Representations than with the other components; and (e) Didactic Orientations toward Teaching Physics directed Knowledge of Instructional Strategies and Representations inhibiting its connection with other components. This study highlights that the quality of PCK depends on the coherence among the components as well as the strength of individual components. From a methodological perspective, this study demonstrates the possibility to make PCK more visible and accessible by mapping PCK components using Pack Pentagon Model.
\end{abstract}

Keywords: pedagogical content knowledge (PCK); integration of PCK components; teaching expertise.

$\mathrm{P}$ hysics students encounter difficulties with regard to conceptual understanding of physics topics, and this have been attributed to the teacher's inadequate knowledge and hence teacher's poor knowledge of relating and connecting Pedagogical Content Knowledge components (Rollnick \& Mavhunga, 2014). Studies on PCK in different countries examined its nature, models, measurements, teacher's perspective of it, factors affecting it, its components and correlation with other knowledge domains, yet the speculation of many teachers on teaching by relating the components of PCK is limited (Park \& Chen, 2012). Locally in Nigeria, the concept of PCK in Physics is still new as very little has been done on it. While the students poor conceptual understanding of physics concepts persists as is reflected in their performance in external examination results (Chief Examiners Report of WAEC $2015 \& 2020$ ). It is obvious that the nature of physics teachers PCK which is a measure of how they integrate the components in other to transform their content knowledge into forms or ways that facilitates physics student conceptual understanding need to be visited.

According to Shulman (1987), "PCK is the blending of content and pedagogy into an understanding of how particular topics, problems, and issues are organized, represented, and adapted to the diverse interests and abilities of students and presented for instruction." Since Shulman's discovery of the concept of PCK, scholars have worked on the concept and consequently, the concept has been interpreted in multiple ways according to different scholars and research agenda, each pointing to a different quality, characteristic, context, attribute, behavior, etc. (Park \& Oliver, 2008a; Van Driel, Verloop, De Vos 1998). As varied as the works of scholars and their construct of PCK, so are their views on the components of PCK. In spite of the varied construct and components, the blending of components in the context of facilitating student learning is the key to conceptualizing PCK (Park \& Oliver, 2008a; Van Driel et al., 1998). They also agreed that effective teaching takes place when PCK components are integrated in a coherent way because they interact in a highly complex way (Laughran, Berry \& Mulhall, 2006; Van Driel, et al, 2002; Park \& Oliver, 2008).

Given the importance of the coherence among the components, many researchers have explored how the components interact with one another to shape the whole structure of PCK However, those studies have focused on only one or two components, examining how a particular component is related to another component (e.g., Cohen \& Yarden, 2009; Veal \& Kubasko, 2003), or how the development of one component influences a teacher's whole PCK and practice (e.g., Kamen, 1996; Matese, 2005). 
Consequently, the nature and dynamics of the interaction among the components through which they are integrated into PCK have not been fully resolved.

Understanding each component in depth and independently from others can serve as a conduit to enhance our knowledge of PCK. Given the integrative aspect and complexity of PCK, however, to provide insightful implications for practice, it is necessary to investigate how all components interact with one another and how they are integrated into PCK that enables a teacher to transform content knowledge into instructional events from a more holistic perspective. Abell (2008) argues that in order to understand the quality of PCK, researchers must attempt to understand the interaction of the PCK components in addition to examining individual components. Friedrichsen, Van Driel, and Abell (2011) also critiqued that research on the PCK of science teachers typically focus on individual PCK components paying no attention to their relation to each other. The Pentagon model as presented by Park defines PCK as an integration of five components which are; orientation towards teaching science, knowledge of student understanding, knowledge of science curriculum, knowledge of instructional strategies and representation and the knowledge of assessment of science learning (Park \& Oliver, 2008b). The components are presented as the five ends of a Pentagon with connecting line between them showing that they are mutually related to one another. Though, the lines do not show the strength of each interaction, but this model gives a good illustration that makes PCK easy to understand and emphasizes that the quality of a teachers PCK can be understood from the manner in which the components are mutually integrated. This study was conceptually grounded in the Park's Pentagon model.

\section{LITERATURE REVIEW}

Park Pentagon Model of PCK components integration as developed by Park and Chen (2012) was largely drawn from the work of Grossman (1990), Tamir (1988), and Magnusson, Krajcik, Borko, (1999). The pentagon model was first constructed through a comprehensive literature review and then elaborated through empirical tests against the model (Park \& Oliver, 2008a, 2008b). Grossman's four knowledge domains for teaching (i.e., Pedagogical Knowledge (PK), PCK, Subject Matter Knowledge (SMK), and Knowledge of Context) provided a theoretical foundation that helped conceptualize PCK in relation to other teacher knowledge domains in developing the pentagon model. With the conceptualization of the four knowledge domains for teaching, PCK is then defined as an integration of five components represented in the pentagon model: (a) Orientations toward Teaching Science (OTS), (b) Knowledge of Students' Understanding in Science (KSU), (c) Knowledge of Science Curriculum (KSC), (d) Knowledge of Instructional Strategies and Representations (KISR), and (e) Knowledge of Assessment of Science Learning (KAs).

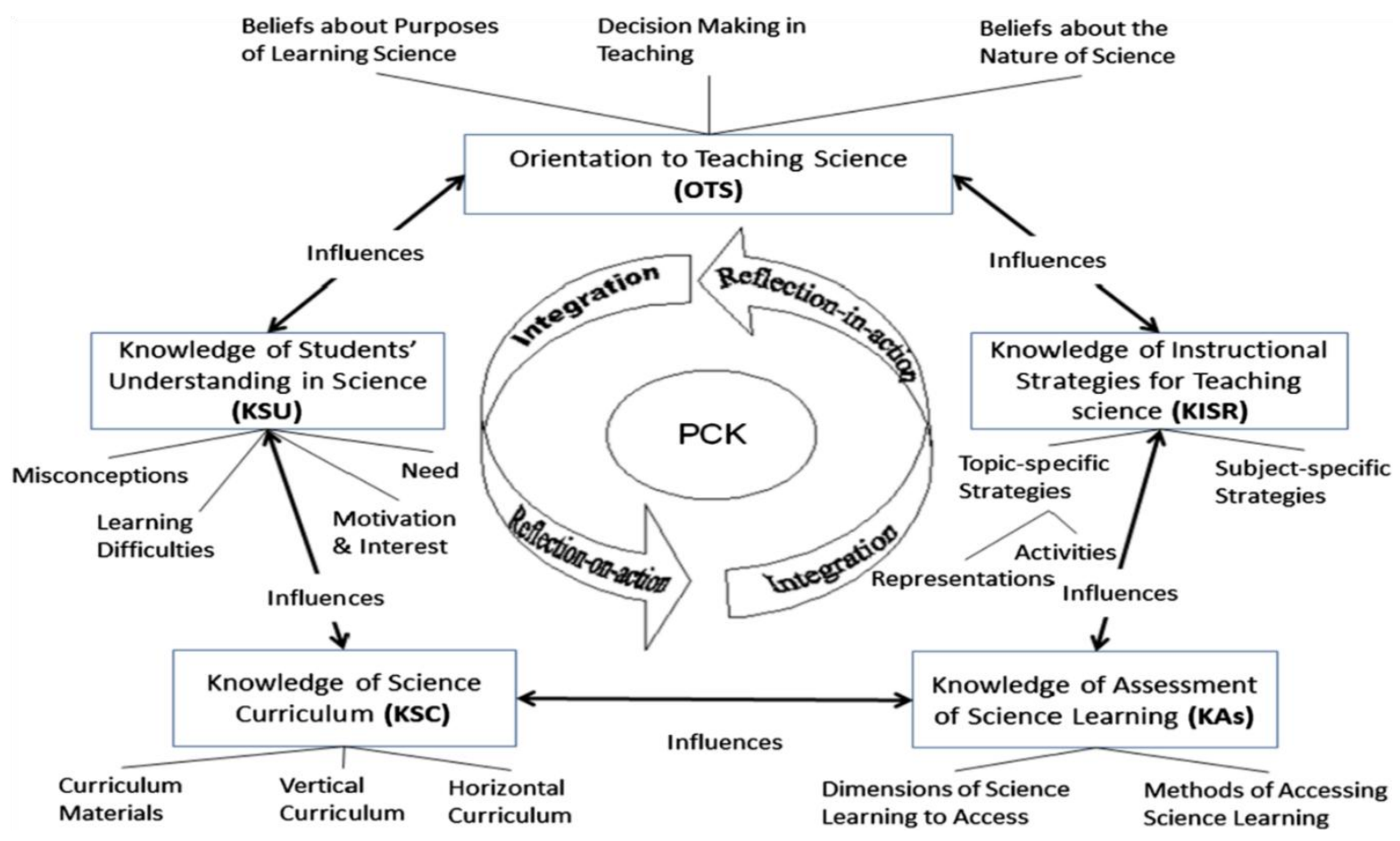

Figure 1. Park's Pentagon model of PCK for teaching science (modified from Park \& Chen, 2012 by rearranging the components and adding their abbreviations).

This model implies that PCK for effective teaching requires the integration of the components in complicated ways because lack of coherence among the components can be problematic in developing PCK. In other words, strong PCK has all components connected to each other strongly enough to enable the whole structure of PCK to function for 
scaffolding student learning. In this regard, an increase in a single component without a corresponding increase in the others may not be sufficient to change the whole PCK structure to stimulate changes in practice (Park \& Oliver, 2008a). The integration among the components is accomplished in a way that strengthens the coherence among the components through complementary and ongoing readjustment motivated by both reflection-in-action and reflection-on-action (Nilsson, 2008; Park \& Oliver, 2008b). The Park's pentagon model served as both the conceptual and analytic frameworks for this study.

Studies to understand the integration of PCK components have been conducted mainly by two approaches. Spaull (2013), describes a qualify teacher as someone who has obtained a requisite level of professionalism (values). He joined the terms subject matter knowledge and content knowledge. He noted that subject matter content knowledge consists of an explanatory framework and the rules of evidence within a discipline which necessitate acquisition of domains knowledge within the discipline. Akinyemi (2016) did a study on pre-service teachers' development of topic specific pedagogical content knowledge (TSPCK) in kinematics and transferability of PCK competence to a new physics topic. The study investigated the extent to which focus on kinematics improves pre-service teachers' PCK in the selected topic and possible transferability of the learnt pedagogical competence to a new physics topic - electric circuits. The study used mixed methods research approach to investigate TSPCK in pre-service teachers. The study was located in a methodology class of Twenty-three (23) 4th year physical science majors' students. The study included an intervention where the theoretical framework for TSPCK was used to introduce the construct in Kinematics. The intervention explains each of the five components of Topic Specific PCK using the knowledge concepts of Kinematics. Data were collected using three instruments: an instrument measuring content knowledge in kinematics; an instrument measuring the quality of TSPCK in kinematics administered as a set of pre/post intervention tests; and an instrument measuring transferability of learnt competence in planning for teaching a new topic electricity. The pre-service teachers' written responses to the TSPCK kinematics tool were analyzed qualitatively and quantitatively. Both methods of analysis from the study revealed that the pre-service teachers improved in their quality of TSPCK in kinematics following the intervention. It was also found out that the pre-service teachers' improvement in the quality of TSPCK in kinematics was as a result of rigorous engagement with the TSPCK components at varying degrees. Suh and Park (2017) did a study on exploring the relationship between pedagogical content knowledge (PCK) and sustainability of an innovative science teaching approach. The aim of the study was to identify common patterns in interactions among orientations and knowledge bases of PCK of teachers, and explore how those patterns relate to their sustained implementation of the argument-based inquiry approach. The study employed a multiple case study research design. The data were analyzed using PCK mapping and the constant comparative method. The findings from the study shows that Knowledge of Science Curriculum (KSC) and Knowledge of Assessment (KAs) were the least connected components; Knowledge of Assessment (KAs) was infrequently associated with other PCK components.

These previous studies opened a fruitful avenue of exploration toward a deep understanding of how one component relates to another component, to the whole PCK, and further to practice. However, little attention was paid to how individual components are connected with others in a way that organizes, develops, and validates PCK. Therefore, the need to assess this interrelationship with senior secondary Physics teachers using Park Pentagon model.

\section{Purpose of the Study}

The main purpose of the study is to Assessed Senior Secondary School Physics Teachers' Pedagogical Content Knowledge (PCK) Components Using Parks' Pentangon Model. Specifically, the study is intended to achieve the following:

(a) Examine Senior Secondary School Physics teachers PCK components integration in the light of Park's pentagon model through the analysis of lesson sessions.

\section{Research Questions}

(a) How is Senior Secondary School Physics teachers PCK components integrated in the light of Park's pentagon model from the lesson sessions?

\section{RESEARCH METHODOLOGY}

The research adopted a qualitative case study research design. This research design requires a clear conceptualization of the 'case' with its definite boundaries and being reflective of real life situations so as to guide the study. Two Senior Secondary School Physics teachers served as the instrumental cases. This approach enables the researcher to explore differences within and between cases with the aim of replicating findings across cases, as the researcher explores similarities and differences between the cases (Yin, 2013). The pedagogical content knowledge components in the context of Park's pentagon model as possessed by Senior Secondary School Physics teachers' serves as the bounded system for this study. The area of the study was two selected Senior Secondary Schools offering physics in Bauchi metropolis of Bauchi State. Twenty five (25) teachers holding a minimum of B. Sc (Ed.)/B. Tech (Ed.) and B. Sc. Physics that are qualified to teach Ordinary Level Physics in public Senior Secondary Schools within Bauchi State constitute the population for the study. A purposive sampling technique was used to select two Physics teachers [each possessing a B. Tech (Ed.) Physics degree] from this population participated in the study. These teachers were 
given pseudo name the female was named Aisha and the male was Bala. At the time of the study Aisha was 35years old with 7 years teaching experience and Bala was 33years old with 3 years teaching experience in the same public school. Multiple sources were used as instruments for data collection n, which includes classroom observations, semi-structured interviews, teacher's lesson plans, audio recorder and video-taper, these instruments were used in line with the nature of the study. A semi structured pre-observation interview, followed by a classroom observation and finally a semi structured post observation interview. The pre-observation interviews contains questions that deals with the participant's teaching backgrounds, orientations to science teaching, and knowledge of teaching the lesson in question, and also the planning of the lesson; which focuses on teachers' planning of the lesson to be observed in terms of the objectives of the lesson, what they took into consideration in planning it, assessment plan, etc.

Classroom observation was done to capture the teacher's manifestation of PCK in action. It is a follow up to the pre-observation interview session to see how the teachers translate their plans and knowledge to their students. the teacher's orientation to science teaching, the teachers knowledge and application of the curriculum, the knowledge of how the students learn and their misconceptions, the knowledge of instructional strategies and representations, and their knowledge of assessments of student learning. A Post observation Interviews was carried out which provide access to some internal bases behind the teacher's action and what they know. Because PCK appears in the planning, interactive, and post-active of teaching (Hashweh, 2005), after each observation, a post-observation interview was conducted to understand each teacher's reflection on the lesson, especially about their thoughts on several interesting classroom incidents noted by the observer.

Data was analyzed using Verbatim Transcription of audio recorded interviews. PCK evidence reporting Table as analytic tool is a PCK scenes in this study showing the interaction of two or more components. So, as a component is coded, it is done along with other component connected to it as manifested in the PCK scene. The same table was used to code the semi - structured interview session and clarifications to the codes were made with other data sources. Codes in the subcategories are tallied to give a complete manifestation of that component in relation to other component.

In-depth analysis of explicit PCK (Park \& Oliver, 2008a) was also used and in this method the researcher first identifies a scene from videotaped instructional sessions that revealed a teacher's PCK according to the operational definition of PCK, that is, PCK as an integration of two or more components in the Pentagon model. Once any scene is observed that indicated the presence of two or more components of PCK, it was followed by a detailed description in terms of: (a) what took place, (b) the knowledge component possessed by the teacher as captured by the PCK Evidence Reporting table and (c) the reason behind what took place.
Enumerative approach (LeCompte \& Preissle, 1993), and the constant comparative methods (Strauss \& Corbin, 1990) were also part of the data analysis method employed. After identifying a scenario in which PCK components were integrated as explained in the in-depth analysis of explicit PCK described before, connections were indicated among the components integrated using the Pentagon model as a guide.

Constant comparative method was used to compare and contrasted the data to those from enumerative approach and the in-depth analysis of explicit PCK in order to provide methodological triangulation (Denzin, 1998).

\section{RESULTS AND DISCUSSION}

\section{Case Study of Bala's Lessons}

\section{Description of Bala's First Lesson (speed, velocity and acceleration):}

The class session has three PCK scenes in line with the definition of PCK in this study. The first scene which lasted for 13 minutes deals with the review of previous lesson as an introduction to what the students should know before the lesson on speed, velocity and acceleration was presented. It also included the presentation and discussion on the concept of speed. The second scene which was longer lasted for 24 minutes and focuses on solving a simple mathematical problem on speed, definition and explanation of the concept of velocity, calculation on velocity and a detailed discussion on acceleration. The third scene deals with the teacher's evaluation, summary and conclusion of the lesson lasted for 7 minutes

The class started with the teacher asking a student to wipe the board, and while that is been done, the teacher asked "who can remind us of what we learnt in the previous lesson"? He repeated the question three times without getting any volunteer to respond to the question. He then wrote on the board the topic of the day as "SPEED, VELOCITY AND ACCELERATION". He then briefly recap the previous lesson by reminding the students thus "you were taught in the last lesson about scalar and vector quantities, you were taught that scalar quantities are those quantities that have magnitude without a specified direction, examples are; distance, mass, length, time, density, speed, and so forth, while vector quantities are those quantities that have both magnitude and a specified direction, examples are; displacement, velocity, acceleration and so forth.". After the brief introduction, the teacher started with the definition of speed which he wrote on the board and asked the students to voice out the definition. "Speed (S) is defined as the rate of change of distance" he went further to explain the definition with other expressions one of which he stated speed is the total distance covered divide by the time taken to cover that distance. While he was explaining some students were seen copying the definition he has written on the board without paying attention to the explanations. He stated that speed is a scalar quantity and is measured in meters per second or kilometer per hour. He 
wrote on the board while the students copy the notes as he writes. He wrote the mathematical formula of speed as speed equals distance divide by time, and also wrote the symbolic form of the formula before solving a simple example of speed. That is $\mathrm{S}=\mathrm{d} / \mathrm{t}$

\begin{tabular}{|l|l|}
\hline Example: & A boy walks a distance of 50m in 100s.what is his speed? \\
\hline Teacher: & Explained the question and solved it on the board \\
\hline Teacher: & $\begin{array}{l}\text { Explained that another word for speed could be how fast. } \\
\text { Implying that for every second, the boy covers a distance of } \\
0.2 \text { meters }\end{array}$ \\
\hline Students: & Copied the solution while the teacher explains. \\
\hline Teacher: & $\begin{array}{l}\text { Asked if there is any question thus far and no student } \\
\text { indicated having a question. }\end{array}$ \\
\hline
\end{tabular}

The teacher (Bala) went further to define velocity as "the rate of change of displacement." He explains that "velocity is the change of distance in a specified direction with respect to change in time". He explains displacement to be vector quantity that has both magnitude and specific direction that differentiate it from distance and because velocity is change in displacement it is also a vector quantity and is measured in meters per seconds. The teacher wrote the definition, the mathematical expression and symbols of velocity (v) on the board while the students copy. The teacher ask if there is any question, no student showed interest in having a question so the teacher went ahead with the lesson, solved an example on velocity problem.

\begin{tabular}{|l|l|}
\hline Example: & $\begin{array}{l}\text { A body experiences a displacement of } 100 \mathrm{~m} \text { in } 20 \text { seconds, } \\
\text { what is the velocity of the object? }\end{array}$
\end{tabular}

The teacher re-explains velocity to emphasize the aspect of specified direction in the concept of velocity "as a change in direction with time is a change in velocity too", then proceeds to explain the solution to the example on the board. The teacher asked if there is any question, no student indicate having a question, the teacher randomly calls five different students by name asking them if they have questions to which they all responded negative. The students were faithful in copying the notes on the board. The teacher advances to the last aspect of the lesson which is acceleration: the teacher defines "acceleration as the rate of change of velocity with respect to time" the students were made to repeat the definition before the teacher wrote it on the board with its formula, S.I unit and symbol. The teacher solved a question on acceleration too and asked the students for questions and when no question arose, the class came to an end.

\section{In-depth Analysis of Explicit PCK of Bala's First Lesson}

For the sake of reducing the quantity of data presented, a description of the first PCK scene is shown in other to explain the analysis process, the description of the other two episodes will not be presented but will be captured in the enumerative approach analysis that summarizes the whole analysis in the lesson.
What the teacher did. The teacher involved the students by asking them to wipe the board, he asked questions about their previous knowledge, wrote the topic on the black board, did a brief recap of key points in the previous lesson, defined speed and asked the student to read and repeat the definition, and then added explanations to the definition of speed. The teacher also wrote the mathematical formula and defined all the symbols and their units.

\section{The teacher's knowledge component as captured by the PCK} evidence reporting table

Under the component of orientation to teaching science, the "didactic" was coded, under the component of knowledge of student "background" was coded, under the component of knowledge of curriculum "vertical curriculum" was also coded, under the component of knowledge of assessment "students learning goals." was coded, under the component of knowledge of instructional strategies and representations, "etc (lecture)" was coded as type of activities and "narrative: stories" was coded as type of language devices

Reasons behind the scenes. From the interview sessions and other data sources, the following information were gathered relevant to explain the scenes.

\begin{tabular}{|l|l|}
\hline Q1 Pre-observation Interview: What is science teaching in your mind? \\
\hline BALA: & $\begin{array}{l}\text { I see Physics teaching as a process of transferring the knowledge } \\
\text { of scientific laws and principles to the student, it is more of the } \\
\text { teacher telling or should I say teaching the student the theories } \\
\text { and laws guiding our everyday life. }\end{array}$ \\
\hline $\begin{array}{l}\text { Q2 Pre-observation Interview: Could you tell me the reasons for learning } \\
\text { science in Senior Secondary Schools? }\end{array}$ \\
\hline BALA: & $\begin{array}{l}\text { The goals of learning Physics in senior secondary schools are: to } \\
\text { equip the students with the knowledge of fundamental scientific } \\
\text { laws and formulas, to prepare them for science courses in the } \\
\text { tertiary institutions and also to make them understand the } \\
\text { principles in play in their environment. }\end{array}$ \\
\hline
\end{tabular}

It was clear from the answer to the above pre observation interview questions that the teacher's orientation is more of facts telling, no wonder when the teacher asked the students thrice what they learnt from the previous lesson and no one responded, he went ahead to narrate the previous lesson then proceeded to his current lesson by defining speed, asked the students to read and repeat then proceed to explanation. The teacher does more of the talking and the students listen and copy the note which reflects more of didactic orientation to science teaching as seen in the code on orientation to science teaching.

Q6 Pre-observation Interview: What kinds of things do you take into consideration in planning this lesson?

BALA: $\quad$ I considered what the students already know, what they will letter learn at this level and the instruments available to teach this lesson. The fact that the students are familiar with the concept of scalar and vector quantities being that $i$ taught them in the previous lesson, the place of the topic in the curriculum and also the capabilities of the students also help me in planning this lesson. The place of the topic in the curriculum and also the capabilities of the students also help me in planning this lesson.

Having identified his orientation to be didactic, it was linked to what the students already know, as the first step taken by the teacher was a review of what they were taught in the previous lesson. In Q6 above, his response was focused on their previous lesson which is the background the students are 
having that links to the current lesson. So in line with the first PCK scene the teacher's knowledge of student is directed to be knowledge of their previous lesson relevant to the current lesson so the link to the teacher's orientation is the teacher's knowledge of the student previous knowledge (background to the current lesson).

Q2 Post observation Interview: How is the topic linked to the syllabus and other important topics?

\begin{tabular}{l|l} 
BALA: & The topic is treated in first term in their SS 2 class as build-up of
\end{tabular} concepts learnt in lower class and also to prepare for equations of motion and more complex physics concepts they will be encountering this SS 2 and before their external examination.

The teacher's orientation was also directly linked to his knowledge of Physics curriculum, from the PCK scene in view, the teacher reviewed by defining scalar and vector quantities with their examples after which he went straight to the topic of the day by defining speed which is a combination of two scalar quantities. The teacher knows the position of the topic in the syllabus and what comes before it and after it. So after treating the concept before it which is scalar and vector quantities, he went ahead to speed knowing where to stop in the current lesson to prepare them for the topic on equations of motion this show his vertical knowledge of the curriculum.

Q3 Pre-observation interview: What are your goals for this unit you are about to teach? And why?

I want the students to be able to define speed, velocity and acceleration, I want them to be able to differentiate between

BALA: speed and velocity and also to do simple calculations using the formula for speed, velocity and acceleration because a good knowledge of these will enhance their understanding of concepts ahead, it will prepare them for other Physics topics.

The knowledge of students was connected to the knowledge of assessment as the teacher knows what to assess in the current lesson. So he defined speed, wrote it on the board then asked the students to define it, which they did, this is in line with his goals for the lesson. His stated goal guides what he is to assess and how to assess it. He wanted them to be able to define so after explaining he asked them to define which they did.

The knowledge of assessment which is seen in the teachers goals captured within this PCK scene is for the students to be able to define speed. This was linked to the knowledge of instructional strategy and representation chosen by the teacher. The lesson in this PCK scene was more of "lecturing" as the teacher was predominantly in charge of the talking and only got the students involved when he needed to assess his stated goal, then the link between the knowledge of assessment and instructional strategies and representation.

\section{Enumerative Approach of PCK components integration}

A PCK Map cull out from the Pentagon Model of PCK was used as an analytical device (Park \& Chen, 2012). This PCK Map was chosen in order to present the integration of PCK components in a clear an explicit manner as part of the enumerative approach (LeCompte \& Preissle, 1993). From the in - depth analysis of explicit PCK described earlier, once a PCK scene is identified which comprises two or more components being integrated; a connecting line was drawn on the PCK map joining the two components. The two components so joined must have at least a special connection. Though the connecting lines does not really depicts the strength of connections, as all connections carries the same single line for ease of analysis. In other words, even though individual connections between component pairs may differ in strength, each has been given a single connection and are counted as ' 1 .' For instance, if the components OTS (Orientation of Science Teaching), KSC (Knowledge of Science Curriculum), and KAs (Knowledge of Assessment of Science Learning were seen to interact together in a given PCK scene, one connection was recorded between any two of the three components as depicted in Figure 2.

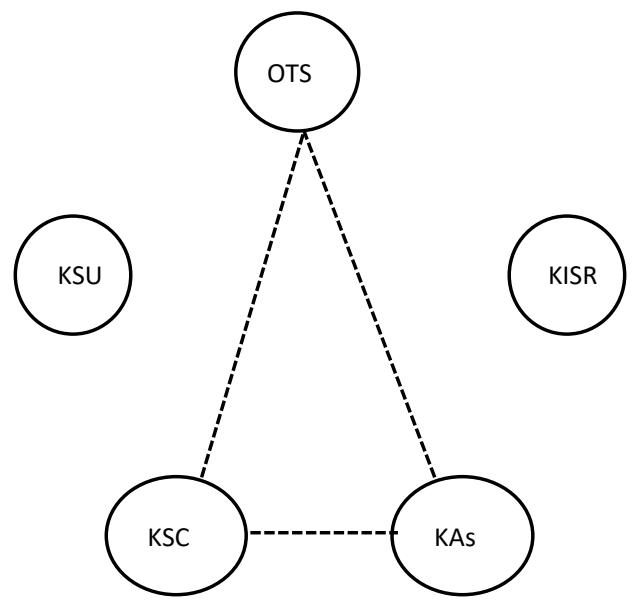

Figure 2. An Illustration of PCK Components Map

The same procedure was repeated for the other connections in a given PCK scene and all the PCK scenes in a given lesson session. The map below shows Bala's integration of the PCK components in his first lesson.

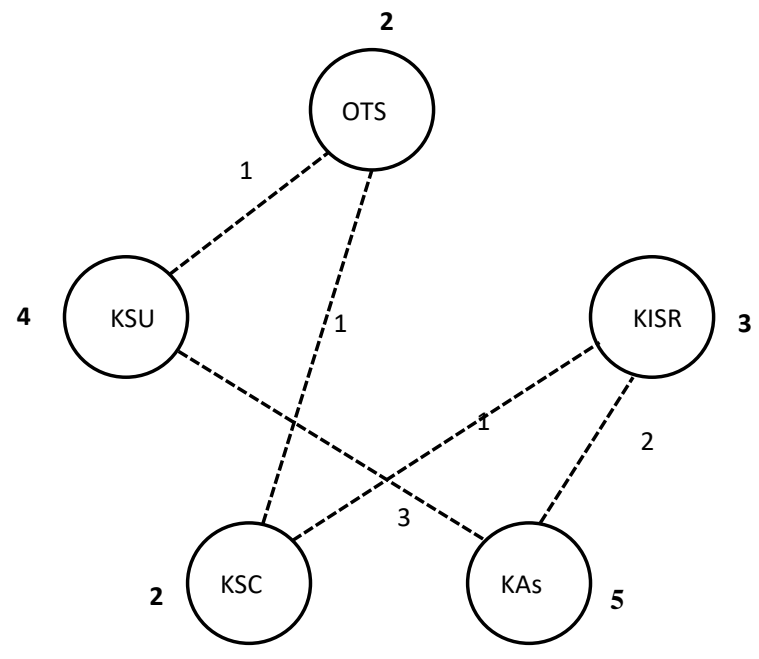

Figure 3. PCK Map of First Bala's Lesson 
Description of Bala's Second Lesson (equations of uniformly accelerated motion):

Four PCK scenes were identified in this second lesson, namely; the first scene which is very brief and lasts for 5 minutes deals with the introduction of the lesson by a brief evaluation of the previous lesson, the second scene lasts for fifteen minutes and basically covers where the teacher derives the equations of motion, the third scene lasts for 17 minutes and deals with the teacher solving problems using the equations of motion and the fourth scene lasts for 8 minutes and deals with the evaluation and conclusion of the lesson.

The class started with the teacher asking the students to define concepts in the previous lesson to which two students volunteered to answer and the teacher acknowledges their efforts without expatiating on the definitions. He then introduced the lesson by writing the topic on the board and describing motion as the change in position of a body with respect to time. In presenting the lesson, the teacher defined acceleration, as the change in velocity divide by time taken. He wrote the mathematical representation of acceleration and uses it to derive the first equation of motion given as:

\begin{tabular}{|c|c|c|}
\hline Acceleration & $=$ & change in velocity/ time \\
\hline $\begin{array}{c}\text { Symbolically; } \\
\mathrm{a}=\mathrm{v}-\mathrm{u} / \mathrm{t} \\
\mathrm{at}=\mathrm{v}-\mathrm{u} \\
\mathrm{v}=\mathrm{u}+\mathrm{at}\end{array}$ & $\begin{array}{c}\mathrm{a} \text { acceleration, } \mathrm{v}=\text { final velocity, } \mathrm{u}=\text { initial velocity, } \mathrm{t} \\
\text { ( }\end{array}$ \\
\hline
\end{tabular}

The teacher paused to take questions but when no question when asked, he proceeded to derive the second and third equations of motion respectively after pausing to reply any available question. After deriving the equations, the teacher highlighted the missing parameter in each equation. The students were copying as the teacher derives the equations. The teacher solves three examples that involves the three equations of motions one after the other. In solving the questions the teacher draws the attention of the students to the fact that a body at stationary position has a velocity of zero at that point, and a negative acceleration implies the body is decelerating. To conclude the lesson the teacher gave a class work and walks around the class inspecting the students while they solve it. Because time was up and without marking the class work, the teacher provided the solution on the board asking the students to copy the solution.

\section{In-Depth Analysis of Bala's Second Lesson}

What the teacher did. The teacher defines acceleration, explains its parameter, wrote its mathematical expression on the board, explains the steps in arriving at the equations and asks questions to evaluate if the equations can be identified.

Teacher's knowledge components as captured by the PCK evidence reporting table.

Three knowledge components were captured in this scene interacting with each other. They are Knowledge of student understanding; knowledge of instructional strategies and representation; and knowledge of assessment of science learning. "Learning difficulty" and "need" were coded under knowledge of student understanding, "etc; lecture" was coded under type of activity, "induction" as type of language device was coded and "diagnostic" under type of assessment was coded.

Reasons behind the scene. From the observation and other supporting data, the knowledge of students learning difficult was obvious by the teacher he had said the challenge he is likely to have relates with the students challenges in mathematical aspect of the lesson, so to that effect, he was a bit slower in the lesson delivery at this stage and was keen in explaining mathematical operations with respect to the deriving the equations of motion.

Q3 Pre-observation interview: What are your goals for this lesson?

\begin{tabular}{l|l} 
& I want the students to be able to identify the various equations of
\end{tabular}

BALA: motion and to use them appropriately in solving simple problems on motion.

Q4 Pre-observation interview: What subject matter or concepts do you expects difficulties with the students and how would you help them?

\begin{tabular}{l|l}
\hline The lesson is simple but most of the students, been that they are
\end{tabular} poor mathematically will find it a bit difficult, so I have to take

BALA: my time and gradually explain each step in deriving the equations and write them down together so that they can easily compare and contrast the equations.

It is obvious that Bala knows what the students need is being able to use the equations of motion and that is a good understanding of the various parameters in each equation and the operations joining the parameter. He also knows that the students are a bit poor with mathematics and that may affect their comprehension, so he took a measure to teach this aspect which is to define, explain, write the necessary expressions on the board, wait to be sure the students are okay before going to the next step. The knowledge of students difficulty is linked to the strategies he adopted to overcome that difficulty. The knowledge of their difficulty is also linked to how he assessed their learning.

Q7 Pre-observation interview: How do you plan to assess the students learning on this unit? What evidence are you looking for that the students have been successful in addressing the goal for the lesson?

\begin{tabular}{|l|l|}
\hline BALA & $\begin{array}{l}\text {... because the lesson is progressive, I have to ensure every } \\
\text { step is understood before going to the next step, so as not to } \\
\text { assume they are understanding only to give question on } \\
\text { equation of motion and be disappointed. After each step, I will } \\
\text { wait and observe their concentration level and level of } \\
\text { participation to be sure they are following. I will give a class- } \\
\text { work at the end of the lesson and mark it too. }\end{array}$ \\
\hline $\begin{array}{l}\text { Q3 Post-observation interview: At the cause of teaching, at every junction } \\
\text { of your argument, you keep asking any question? Who is not following? } \\
\text { Are you clear? And it seems those questions dominated your lesson, why? }\end{array}$ \\
\hline BALA & $\begin{array}{l}\text { Yes! Like I said I need them to follow and understand each } \\
\text { step and know how the equations were derived and also be } \\
\text { very familiar with their application. So I have to be evaluating } \\
\text { each step by asking if they are following. }\end{array}$ \\
\hline
\end{tabular}

Bala was particular about the goal and difficulties the students are already having, so he build the pattern of constantly asking questions as he argues the facts narrowing them down to his stated goal. 


\section{Enumerative Approach of Bala's Second Lesson}

As explain in the enumerative approach, the PCK Map of BALA's second lesson is shown below.

\section{Summary of Bala's Lessons before the Intervention}

The figures below shows the summary of Bala's PCK integration of PCK component

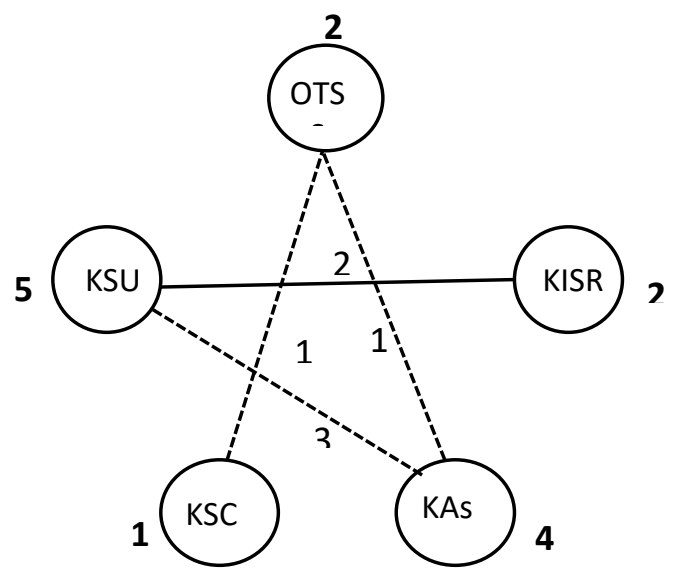

Figure 4. PCK Map of Bala's second Lesson

First lesson

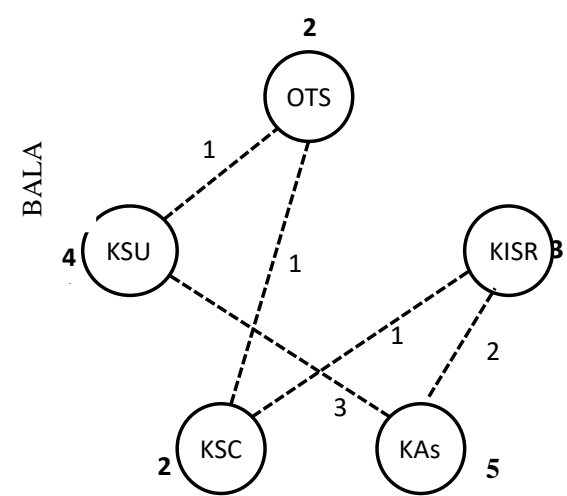

Second lesson

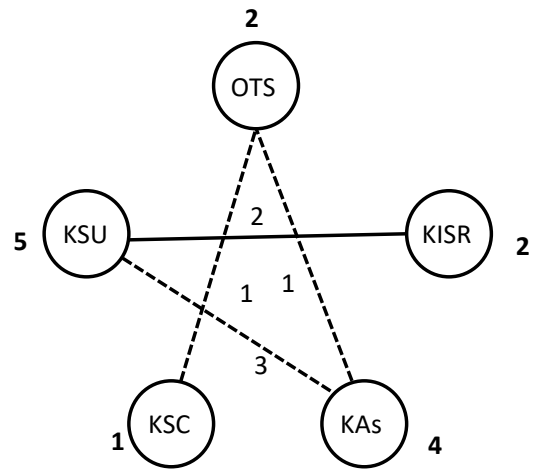

Summation of both lessons

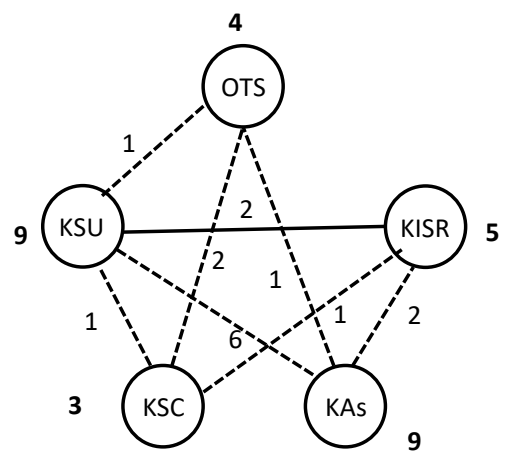

Figure 5. Combined PCK Maps of Bala's lessons

From the PCK map of Bala's first lesson in the figure 6 above, KAS happens to be the most active components that it was integrated 5 times in the lesson. This component was more of questioning technique used at the course of his lesson presentation. The next active component that was more integrated in the lesson was KSU which was integrated 4 times in the lesson with 3 of these occasions it was integrated with KSA. Bala's second lesson was not too different from the first in terms of components integrations as KSA and KSU were the most involved components in the lesson occurring 4 and 5 times respectively and having the highest connection amongst themselves while there was a drop in integrating KISR and KSC which were only integrated once with other component at the course of the whole lesson. Summing up the two lessons shows a strong balance and affinity between KSA and KSU as the strength of his teaching ability with each component being integrated 9 times and on 6 occasions they interacted with themselves.
Table 1: Bala's integration of the PCK components

\begin{tabular}{|c|c|c|c|}
\hline & \multicolumn{3}{|c|}{ Number of components interacting } \\
with it \\
\hline PCK components & $\begin{array}{c}\text { First } \\
\text { Lesson }\end{array}$ & $\begin{array}{c}\text { Second } \\
\text { lesson }\end{array}$ & $\begin{array}{c}\text { Summation of } \\
\text { lessons }\end{array}$ \\
\hline OTS & 2 & 2 & 3 \\
\hline KISR & 2 & 1 & 3 \\
\hline KSA & 2 & 2 & 3 \\
\hline KSC & 2 & 1 & 3 \\
\hline KSU & 2 & 2 & 4 \\
\hline $\begin{array}{c}\text { Average of components } \\
\text { interacting }\end{array}$ & 2.0 & 1.6 & 3.2 \\
\hline
\end{tabular}

The integration of the components was isolated in the first lesson as an average of only 2 components were integrated at every scene where components integration were noticed as seen in Table 1. The average of components integration in this lesson dropped to 1.6 in the second lesson 
showing a poor integration of the PCK components. The summation shows an average of 3.2 as the integration of the components and each component is fairly integrated with 3 other components except KSU that has four which is close to a good integration of PCK components.

\section{Case Study of Aisha's Lesson}

\section{Description of Aisha's First Lesson (Speed, Velocity and Acceleration)}

The lesson has four PCK scenes which are: first scene lasted for 7 minute and focuses on background for the lesson, definition and explanation of the concept of speed, second scene lasted for 14 minutes and it reflects the following; the definition and explanation of the concepts of average speed, instantaneous speed and constant speed. Third scene lasted for 13 minutes and covers the definition and explanation of the concept of velocity and forth scene lasted for 11 minutes and deals with the treatment of the concept of acceleration and conclusion to the lesson.

The lesson lasted for about 45 minute and comprises of 54 students few of which came in while the class is ongoing and the teacher cautioned them not to come late to her class again as what has been missed may not be repeated. She wrote the topic on the board then informed the students of what they are supposed to know at the end of the lesson that is, meaning and difference between speed, velocity and acceleration. She then went ahead to review the previous lesson.

She defined speed as the "distance travelled per unit time", she explained that it is also "distance divide by the time to cover that distance". She further stated that "speed is not distance nor is speed time but the ratio of distance to time" she wrote the symbol and mathematical expression of speed on the board explaining what each symbol stands for. She asked if they are understanding and received a positive response. She explained the concept of average speed, uniform speed and instantaneous speed with example to illustrate each one. She defined velocity as the "distance traveled in a specified direction per unit time". She went ahead to differentiate velocity from speed, emphasizing that velocity is a vector quantity which has both magnitude and direction while speed is a scalar quantity which has only magnitude but no direction. She wrote the mathematical expression of velocity on the board defining all the symbols and then gave room for questions. She solved two simple exercises one for speed and the other for velocity. She treated the last aspect of her lesson which is acceleration following the patterns for speed and velocity. She rounded up the lesson and gave out note for the students to copy after she highlighted the objectives for the lesson.

\section{In-depth Analysis of Explicate PCK of Aisha's First Lesson}

Description of the analysis of the last PCK scene is given below.
What the teacher did. She defined acceleration and wrote the mathematical expression on the board, explained the definition and the formula, solved an example using the formula to explain further the concept of acceleration, asked questions by pointing at individuals to answer the questions.

Knowledge components captured by the PCK evidence reporting table

Three knowledge components were captured in this Scene, knowledge of student's understanding, knowledge of instructional strategies and representations and the knowledge of assessment of science learning. Under the knowledge of students understanding, "diversity" and "learning difficulty" were coded and that links o the codes under knowledge of assessment of science learning "formative" was coded and that links to the knowledge of instructional strategy was coded "problem solving" was coded as type of activity while "recall/ factual questions" as well as "attention focusing questions" were coded as type of language devices.

\section{Reason behind the scenes}

Q3 Post-observation interview: At the cause of teaching, you were selective in asking questions and few questions were left open for any student to answer, you kept calling them by name and asked them question? And it seems some selected students were the focus of your lesson, why?

AISHA: $\quad$ Over time I have known their respective abilities and needs. I know those who won't want to say anything in class yet are focused on all you explain and there are those that the only way to keep their mind in class is to be calling them to participate. This guided how I interact with them in the lesson. There are those I need to carry along mathematically and there are those I need to be sure are not misunderstanding what is been taught.

Q7 Pre-observation interview: How do you plan to assess the students learning on this unit? What evidence are you looking for that the students have been successful in addressing the goal for the lesson?

AISHA: $\quad$ I will evaluate the lesson at every step, asking questions to know if they are following, give room for them to ask questions. There are certain students with unique challenges and I will be particular about asking them questions to assess the general class response

Aisha has planned the lesson from the beginning with the nature of her students in mind. She is familiar with their weakness and strength and also familiar with the weak and good students, so she specifically planned the lesson around certain students with the expectation that if they get it, others definitely will get it. This scene particularly reflects student centeredness and the evaluation is done systematically and not at the end of the lesson. Her questioning technique was more of getting the attention of the students and to help them recall what they already know.

\section{Enumerative Approach of Aisha's First Lesson}

The summary of Aisha's PCK integration is shown in the PCK figure below. 


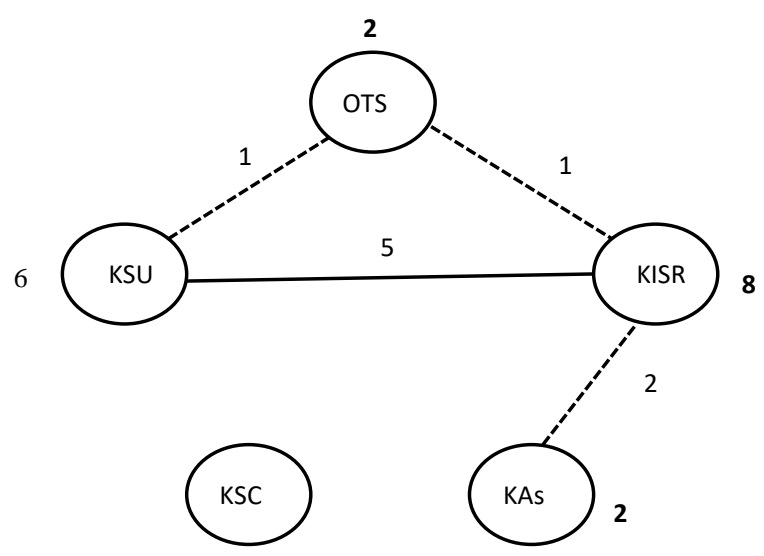

Figure 6. PCK Map of Aisha’s first Lesson

Description of Aisha's second lesson (Equations of uniformly accelerated motion)

The lesson was divided into three PCK scenes which lasts a total of 43 minutes. The first scene deals with recap of the previous lesson, background of the lesson, derivation of the first equation of motion, this lasted for 14 minutes. The second scene lasts for 12 minutes and deals with the other equations of motion and the third scene lasts for 17 minutes and deals with calculations using the equations of motion, evaluation and conclusion of the lesson.

The teacher wrote the topic on the board and after a brief recap of the previous lesson; she stated that the students should know the equations of motion and how to apply them in solving simple problems involving bodies in motion. She asked the students to define acceleration and one of them stated that it is the rate of change of velocity with time. She acknowledged the definition and wrote the mathematical expression then worked out the first equation.

She asked the student to define average speed which a student defined as total distance covered divided by total time taken. She acknowledged the answer and went ahead to explain average velocity as initial velocity plus final velocity divide by two. She proceeded to derive the second and then the third equations of motion. She wrote down the equations, defined their symbols and explained how they are used depending on what is expected to be calculated. To crown the lesson, she copied out questions from the text book one after another to solve by asking the students which is best to calculate the unknown. At the end of solving the questions, she asked if there is any problem with the lesson and the students say no. she asked them to copy the note and them briefly highlight on what has been taught and the students knowing the equations of motion and how to use the relevant one for a given question.

In-depth Analysis of Explicit PCK for Aisha's Second Lesson

A description of the third PCK scene is presented.
What the teacher did. The teacher copied out questions from the textbook one after another in line with the equations he had explained; involved the students in solving the questions by question them and also instructed them to try out some questions on their own.

Knowledge component captured in the PCK evidence reporting table

In this PCK scene; the knowledge of students understanding, the knowledge of instructional strategies and representation and the knowledge of assessment were captured. Under the category of students understanding, "learning difficulty" was captured, under the category of instructional strategy and representation "problem solving" was coded for type of activity, "problem posing questions" was coded and in the category of knowledge of assessment, "students learning goals..." was coded alongside "formative" type of assessment

Reasons behind the scene. In this particular scene that deals with the application of the equations to solve problems copied from the text book, the teacher writes down the question on the board, turns to the students and asked which equation is suited to solve the problem. Initially, the students were guess answering and with proper assessment of the question, they focused on a particular equation, the teacher acknowledged their choice as the correct one, then asked how to apply the formula. The teacher kept asking Questions that poses the problems to the students and waits for them to come up with the best solutions which they did. When they present a wrong answer, the teacher explains why that option is wrong and allows them to think and produce the correct one. The instructional strategy was problem solving and this was linked to students understanding as the teacher posses a question in other correct any misconception the students have and address aspects of learning difficulties. This is also linked to what the teacher assessed in the lesson, that is, the goals important to be assessed. As clearly stated in the lesson, one of the objectives of the lesson is that the students identify the equations of motion and to use them in solving problems.

\begin{tabular}{|l|l|}
\hline Q3 Pre-observation interview: What are your goals for this lesson? \\
\hline AISHA: & $\begin{array}{l}\text { At the end of the lesson, I want to look back and be sure that the } \\
\text { students can derive the equations of motion, know and } \\
\text { differentiate the equations and also use the equations efficiently } \\
\text { to solve problems on motion. }\end{array}$ \\
\hline
\end{tabular}

Q6 Pre-observation interview: What kinds of things do you take into consideration in planning this lesson?

AISHA: $\quad$ I took the students into consideration first, then the materials available to teach this lesson, I also considered the students ability in relation to mathematical competence.

Q7 Pre-observation interview: How do you plan to assess this lesson? What evidence are you looking for that the students have successfully learnt in addressing the goals for the lesson?

AISHA: $\quad$ I planned assessing the lesson by getting feedback at each step of the lesson, asking questions to make the students participate and correct whatever is wrong in their responses guiding them to be more inquisitive and draw out solution from what they already know. I will get feedback from their responses and expressions on their faces. 
This scene in Aisha's lesson shows a combination of problem solving approach and assessment strategy and their integration with students understanding of the lesson.

\section{Enumerative Approach of Aisha's second lesson}

The summary of Aisha's PCK Map for the second lesson is shown below.

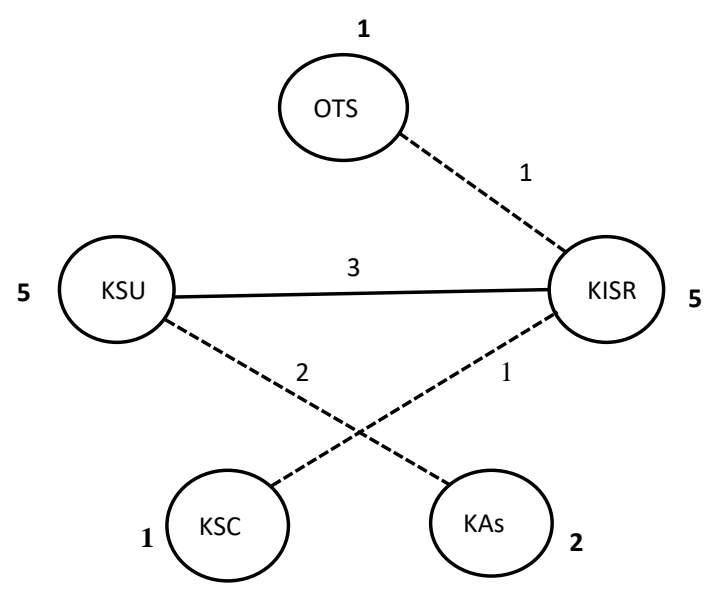

Figure 7. PCK Map of Aisha's second Lesson before Intervention

Summary of Aisha's lessons before the intervention

The summary of Aisha's PCK components integration is given in the figure below.

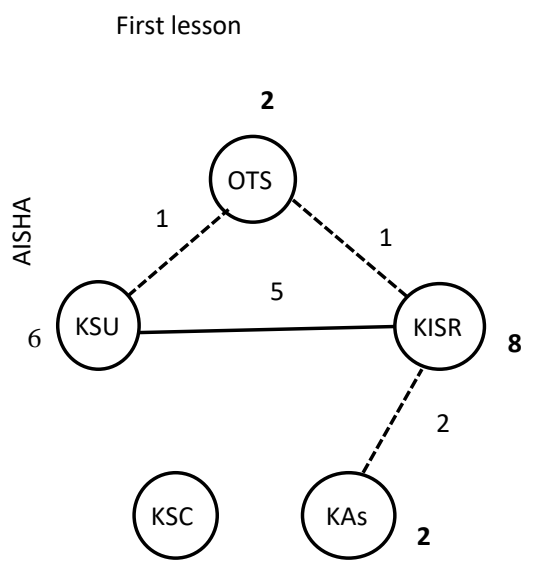

Second lesson

Summation of both lessons
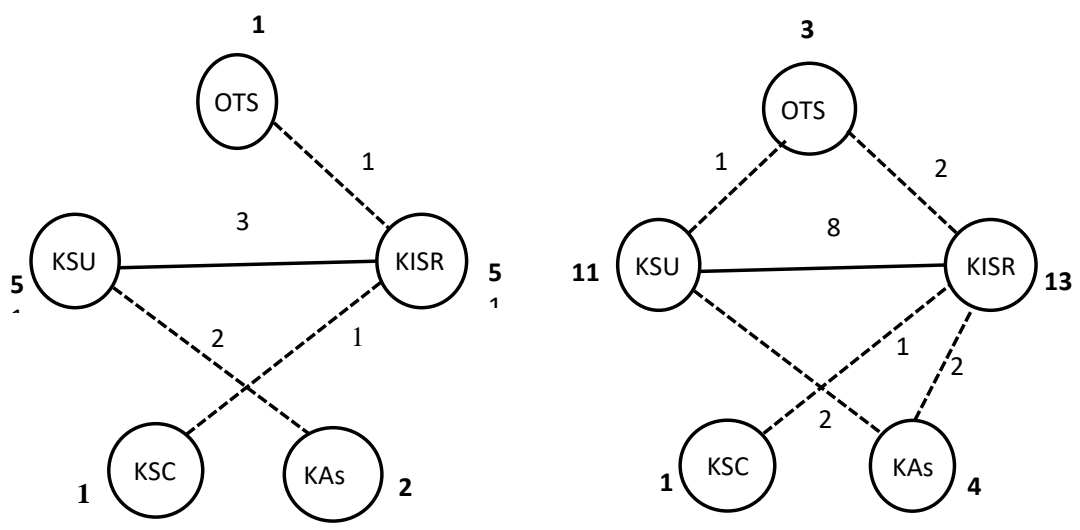

Figure 8. Combined PCK Maps of Aisha's lessons

From the figure above, Aisha's PCK integration was very skeletal in the first lesson with no connection made at all to KSC. The lesson was just centered on the interaction of KSU and KISR and a little connection with OTS and KAs. KSU was incorporated 6 times and 5 of those times are with KISR which was connected 8 times and not a single interaction of KSC with any component. The second lesson was like the first with KSU and KISR having 5 connections each with a poor connection of other components where KSC and OTS are just connected only Once. Aisha shows a poor integration of the PCK components with just KSU and KISR being the strength of the teaching activities.
Table 2: Aisha's integration of the PCK Components

\begin{tabular}{|c|c|c|c|}
\hline & \multicolumn{3}{|c|}{$\begin{array}{c}\text { Number of components interacting with } \\
\text { it }\end{array}$} \\
\hline PCK COMPONENTS & $\begin{array}{l}\text { First } \\
\text { lesson }\end{array}$ & $\begin{array}{l}\text { Second } \\
\text { lesson }\end{array}$ & $\begin{array}{c}\text { Summation of } \\
\text { lessons }\end{array}$ \\
\hline OTS & 2 & 1 & 2 \\
\hline KISR & 3 & 3 & 4 \\
\hline KSA & 1 & 1 & 2 \\
\hline KSC & 0 & 1 & 1 \\
\hline $\mathrm{KSU}$ & 2 & 2 & 3 \\
\hline $\begin{array}{l}\text { Average of components } \\
\text { interacting }\end{array}$ & 1.6 & 1.6 & 2.4 \\
\hline
\end{tabular}


From the above Table the integration of the PCK components shows that in the first lesson, OTS interacted with 2 other components, KISR interacted with 3 other components, KSA interacted with one other component, KSC has no interaction and KSU has 2 interactions. Averagely, the level of integration of her PCK components is at 1.6 which shows a very low mutual involvement of the PCK components which is required for a good teaching and learning exercise.

In the second lesson, while all the components seems to be interacted in the lesson, they are poorly mutually interacted as OTS, KSA and KSC interacted with only 1 other component in this lesson delivery. The much occurrence of KISR and few of KSU brought her average integration of the components to 1.6 which is still very low with her level of experience. The summation of the two lessons brought her average integration of the components to 2.4 out of the expected average of 4 before looking the regularity of the interactions.

\section{CONCLUSION}

Based on the forgone submission it was concluded that, the pedagogical content knowledge (PCK) of secondary school physics teachers was not developed due of lack of coherence among its components. However, with increase in knowledge in some component it was sufficient to stimulate change in the way physics teachers deliver their lessons.

\section{RECOMMENDATION}

(a) Pre-service teachers should be exposed to opportunities for developing and integrating the components of topic-specific pedagogical content knowledge at the level of the teacher training programs.

(b) Also capacity building training workshop on topicspecific pedagogical content knowledge components and their integration should be organized for Inservice physics teachers to upgrade their knowledge and skill in teaching physics.

\section{REFERENCES}

[1] Abell, S. K. (2008). Twenty Years Later: Does Pedagogical Content Knowledge remain a UsefulIdea? International Journal of Science Education, 30(10): 1405-1416.

[2] Akinyemi, O. S. (2016). Pre-Service Teachers' Development of Topic Specific PCK in kinematics and Transferability of PCK Competence to a New Physics Topic. Research report submitted to the faculty of Science Education for the award of Master of Science (MSc.) in Science Education, university of the Witwatersrand, Johannesburg, South Africa.

[3] Bas F. (2016). Pre service secondary mathematics teachers' metacognitive awareness and metacognitive behaviors in problem solving processes.

[4] Cohen, R. \& Yarden, A. (2009). Experienced Junior - High School Teachers' PCK in Light of a Curriculum Change: "The Cell is to be Studied Longitudinally". Research in Science Education, 39: 131-155.

[5] Denzin, N. K. (1998). The Research Act: A Theoretical Introduction to Sociological Methods ( $2^{\text {nd }}$ ed.). New York: McGraw - Hill.

[6] Friedrichsen, P., Van Driel, J. H., \& Abell, S. K. (2011). Taking a closer look at Science Teaching Orientations. Science Education,
95: 358-376.

[7] Grossman, P. L. (1990). The Making of a Teacher: Teacher Knowledge and Teacher Education. New York: Teachers College Press.

[8] Kamen, M. (1996). A Teacher's Implementation of Authentic Assessment in an Elementary Science Classroom. Journal of Research in Science Teaching, 33(8): 859 - 877.

[9] Loughran, J. Berry, A. \& Mulhall, P. ( 2006) Understanding and Developing Science Teachers' Pedagogical Content Knowledge, Rotterdam, The Netherlands: Sense Publishers.

[10] Magnusson, S., Krajcik, J., \& Borko, H. (1999). Nature Sources and Development of Pedagogical Content Knowledge for Science Teaching. Examining Pedagogical Content Knowledge: The Construct and its Implications for Science Education (pp. 95 132). Dordrecht: Kluwer Academic.

[11] Matese, G. (2005). Cognitive Factors Affecting Teaching Formative Assessment Practice, Paper Presented at the American Educational Research Association, Montreal, Canada.

[12] Nilsson, P. (2008). Teaching for Understanding: The Complex Nature of Pedagogical Content Knowledge in Pre-Service Education. International Journal of Science Education, 30(10): 1281-1299.

[13] Park, S. \& Chen, Y. C. (2012). Mapping out the Integration of the Components of Pedagogical Content Knowledge (PCK): Examples from High School Biology Classrooms. Journal of Research in Science Teaching, 49(7): 922 - 941.

[14] Park, S., \& Oliver, J. S. (2008a). Revisiting the Conceptualization of Pedagogical Content Knowledge (PCK): PCK as a conceptual tool to Understand Teachers as Professionals. Research in Science Education, 38(3): 261-284.

[15] Park, S., \& Oliver, J. S. (2008b). National Board Certification (NBC) as a Catalyst for Teachers' Learning About Teaching: The Effects of the NBC process on Candidate Teachers' PCK Development. Journal of Research in Science Teaching, 45(7): 812-834.

[16] Rollnick, M., \& Mavhunga, E. (2014). The relationship of PCK knowledge to practice: A case study of two pre-service teachers teaching chemical equilibrium. Paper presented at the Conference of the Southern African Association for Research in Mathematics, Science and Technology Education, Port Elizabeth, South Africa.

[17] Shulman, L. (1987). Knowledge and Teaching: Foundations of the New Reform. Harvard Educational Review, 57(1): 1-22.

[18] Spaull, N. (2013). South Africa's Education Crisis: The Quality of Education in South Africa 1994-2011. Johannesburg: Centre for Development and Enterprise. Retrieved from http://www.cde.org.za/images/pdf/South\%20Africas\%20Educatio n\%20Crisis\%20N20Sp a \%202013.pdf (accessed March 16, 2017).

[19] Suh, J. K., \& Park, S. (2017). Exploring the relationship between pedagogical content knowledge (PCK) and sustainability of an innovative science teaching approach: Teaching and Teacher Education, 64: 246-259.

[20] Tamir, P. (1988). Subject matter and related pedagogical knowledge in teacher education. Teaching and Teacher Education, 4, 99-110.

[21] Van Driel, J. H., De Jong, O., \& Verloop, N. (2002). The development of preservice chemistry teachers' pedagogical content knowledge. Science Education, 86, 572-590.

[22] Van Driel, J. H., Verloop, N., \& De Vos, W. (1998). Developing science teachers' pedagogical content knowledge. Journal of Research in Science Teaching, 35, 673-695.

[23] Veal, W. R., \& Kubasko, D. S. (2003). Biology and geology teachers' domain-specific pedagogical content knowledge of evolution. Journal of Curriculum and Supervision, 18(4), 334-352.

[24] Yildiz and Akdag (2017). Effect of metacognitive strategies on prospective teachers metacognitive awareness and self-efficacy belief. Journal of education and training studies vol. 5, No. 12 ISSS 232-805. 
APPENDIX A

PCK Evidence Reporting Table

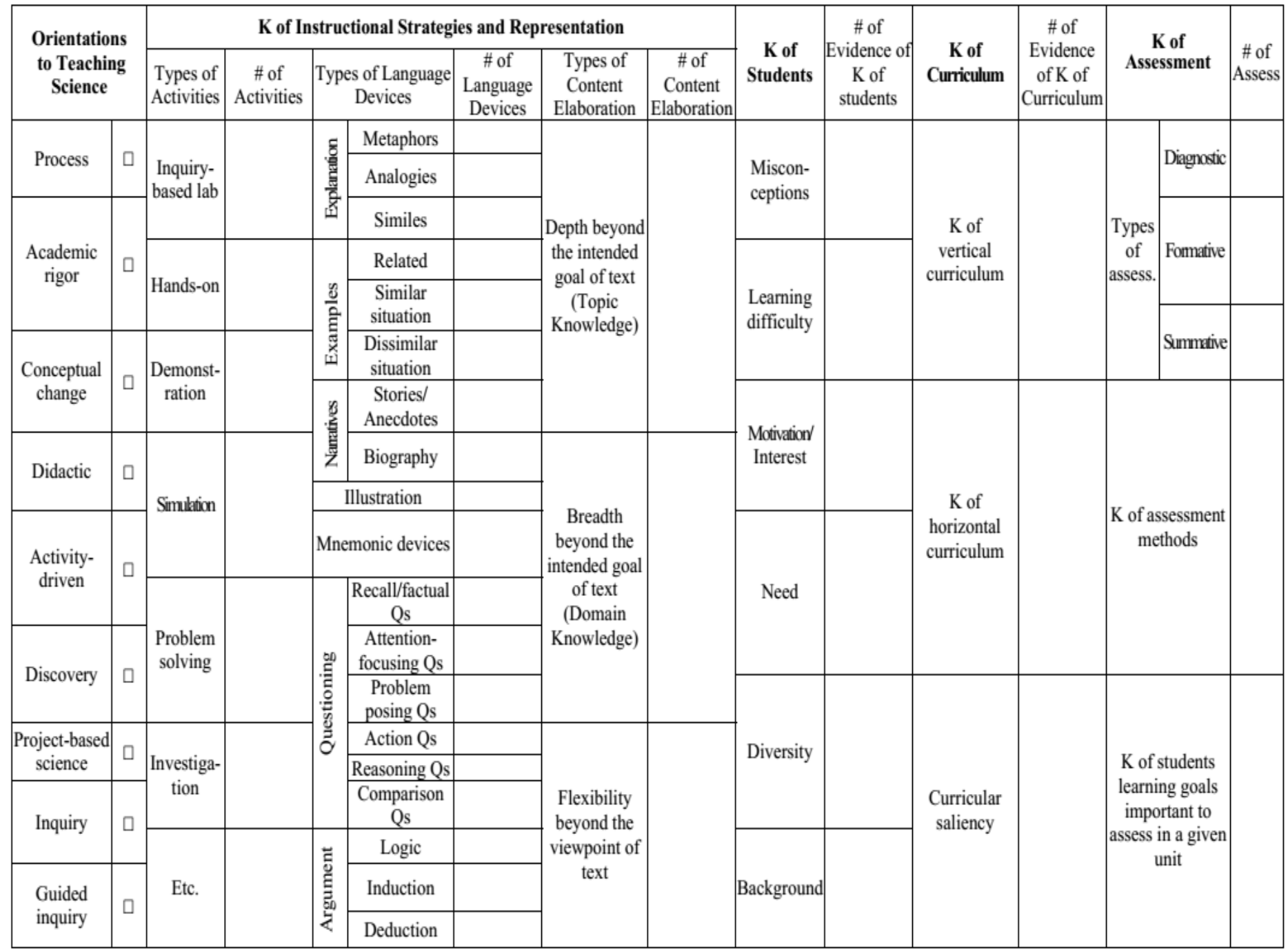

